\title{
O EKSPLETIVNOJ NEGACIJI U FRANCUSKOM, ITALIJANSKOM I SRPSKOM JEZIKU**
}

Ekspletivno (pleonastično) ne osobenost je ne samo romanskih, već i velikog broja jezika različitih jezičkih jezičkih grupa. S obzirom na to da smo se u nekim ranijim izučavanjima bavili ovom pojavom u okviru kompletivne rečenice u francuskom i srpskom jeziku, u ovom radu postavili smo sledeće ciljeve: sagledavanje upotrebe ekspletivne negacije kako u kompletivnim, tako i u ostalim zavisnim rečenicama u francuskom jeziku i sintaksičkih uslova pod kojima se ona realizuje, te poređenje dobijenih rezultata sa ekvivalentnim rečenicama u italijanskom i srpskom jeziku, uz primenu kontrastivne analize.

Ključne reči: ekspletivna negacija, pleonastična negacija, frazeološka negacija, francuski, italijanski, srpski

\section{UVODNE NAPOMENE}

Neposredan povod za ovaj rad jeste članak Pleonastic negation from a cross-linguistic perspective (Zonko Dilković - Ilc, 2017) u kojem se razmatra pojava ekspletivne (u terminologiji autora pleonastičke) negacije u različitim jezicima. Autori, između ostalog, zaključuju da se ona javlja u sličnim sintaksičkim okruženjima, ali da postoje varijacije u stepenu (ne)obaveznosti takve negacije. Tako na primer, u romanskim jezicima ona je uvek fakultativna, dok u slovenskim jezicima ona može da bude i obavezna ${ }^{1}$.

\footnotetext{
*ruzica.seder@ff.uns.ac.rs

** Ovaj rad je nastao u okviru projekta Ministarstva nauke, prosvete i tehnološkog razvoja Republike Srbije (Broj projekta: 01600)

${ }^{1}$ Prema autorima, u romanskim jezicima rečenice u kojima se ona javlja nikada nisu $u$ indikativu, dok u slovenskim jezicima glagolski oblici upotrebljeni u njima mogu da budu i indikativno i modalno upotrebljeni. Sa ovom tvrdnjom se ne slažemo u potpunosti, jer su recimo u francuskom jeziku komparativne rečenice za nejednakost, u kojima je ekspletivno $n e$ veoma frekventno, uvek $\mathrm{u}$ indikativu. $\mathrm{U}$ ovom radu mi se nećemo baviti glagolskim načinom u ovim rečenicama, jer je to bila tema nekih naših ranijih radova (Seder 2008; Seder, 2011; Seder, 2011a).
} 
U skladu sa tim, smatrali smo interesantnim da uporedimo status i frekvenciju ekspletivne negacije $u$ francuskom i italijanskom kao romanskim jezicima sa jedne strane, u odnosu na srpski kao slovenski jezik ${ }^{2}$.

U literaturi vezanoj za francuski jezik, pored (najčešće korišćenog) termina ne explétif, koriste se i termini abusif, redondant, pléonastique (Milošević, 1997 : 37), što upućuje na stavove autora vezano za ovu pojavu. Naime, većina autora smatra ga semantički i sintaksički irelevantnim ${ }^{3}$, navodeći samo to da je reč o osobenosti negovanog francuskog jezika (Dubois -Lagane, 1993), te je njegov efekat samo stilski.

Ipak, pojedini autori mu pripisuju određenu semantiku : Damuret i Pišon (Damourette - Pichon, 1911 : 36), negujući psihološki pristup gramatici, njegovu upotrebu objašnjavaju kao nesklad između sadržaja glavne i zavisne rečenice, dok drugi (Poisson-Quinton, Mimran \& Mahéo-Le Coadic, 2004 : 235) smatraju da ono nosi ideju implicitne negacije : Je crains qu'il ne parte [= Je ne veux pas qu'il parte]. I Marko Papić prepoznaje anaforičku funkciju ekspletivnog ne, jer ono „vraća misao na prethodni kontekst, označavajući da je u njemu sadržana neka negativna ideja“" (Papić, 1992 :189).

U italijanistici se ova pojava naziva frazeološka negacija, pleonastičko non (Terić, 2005) ili frazeološko non (Serianni, 2005), i takva negacija uvek je fakultativna. Serijani zaključuje da „njegovu upotrebu - uprkos različitim pokušajima objašnjenja - treba smatrati nepredvidivom " (Serianni, $2005: 616$ ).

U srpskom jeziku govori se o ekspletivnoj ili suvišnoj negaciji (Popović, 1994 ; Stanojčić - Popović, 1994), koja je nekada fakultativna, ali nekada i obavezna.

\section{ANALIZA KORPUSA}

Ekspletivno ne u francuskom jeziku javlja se u sklopu nekih kompletivnih rečenica, u jednom tipu temporalnih rečenica, u komparativnim rečenicama za

\footnotetext{
${ }^{2}$ Sa formalne strane, u francuskom jeziku, koji ima dvočlanu negaciju, reč je o upotrebi samo prvog dela negacije (discordantiel) koji se tada naziva ne explétif, a drugi deo negacije - forclusif (pas, rien, personne, jamais, ...) biva izostavljen. U italijanskom i srpskom jeziku, koji imaju jednočlanu negaciju, nema te formalne razlike, s tim što druge sintaksičke datosti upućuju da nije reč o pravoj negaciji.

3 Vilme detaljno navodi pojedinačne stavove autora prema kojima je ono u potpunosti suvišno (Wilmet, 2003 : 637).
} 
nejednakost, pojedinim finalnim i pojedinim hipotetičkim rečenicama ${ }^{4}$. U ovom poglavlju ćemo, polazeći od francuskog, uporediti datosti vezane za ovakve konstrukcije $\mathrm{u}$ francuskom sa istovetnim konstrukcijama u italijanskom i srpskom jeziku, na korpusu ekscerpiranom iz savremenih francuskih romana i njihovih objavljenih prevoda na italijanski jezik i srpski jezik.

\subsection{Kompletivne rečenice ${ }^{5}$}

U okviru kompletivnih rečenica, prema literaturi, ekspletivno ne javlja se nakon glagola bojazni, glagola empêcher (sprečiti, sprečavati), kao i glagola nier (poricati) i douter (sumnjati) kada su u odričnoj ili interogativnoj konstrukciji. Ono što je zajedničko ovim glagolima, jeste specifičnost njihove semantike: izražavaju želju govornika (ili protagoniste) da se neka radnja ne izvrši ili pak njegovo negiranje realizacije radnje zavisne rečenice, bilo da je ono eksplicitno (nier) ili implicitno (douter).

\section{1.a. Glagoli bojazni}

Reč je o sledećim glagolima i glagolskim izrazima6: craindre, avoir peur, redouter, appréhender, trembler i sl. Kod ovih glagola govornik izražava strah da će se desiti nešto što on evidentno ne želi da se desi. Damuret i Pišon (Damourette Pichon, 1911: 36) ovu upotrebu ekspletivnog ne objašnjavaju činjenicom da je strah upravo nesklad između činjenice da postoji mogućnost realizacije neke pojave i želje da do te realizacije ne dođe: J'ai peur qu'il (ne) parte (Plašim se da ne ode) kod ovakvog iskaza jasno je da postoji mogućnost realizacije glagola partir koja je u suprotnosti sa željom subjekta glavnog glagola. Prema autorima, kada su ovakvi glagoli upotrebljeni odrično ne pojavljuje se ne, jer nema više nesklada: ili zbog nedostatka mogućnosti da dođe do neželjene pojave, ili zbog nedostatka straha od nje : Je ne crains pas qu'il fasse cette faute/Ne plašim se da će on načiniti/da on načini takvu grešku (Littré, apud: Grevisse, 1973 : 290).

\footnotetext{
${ }^{4}$ Upotreba ekspletivne negacije smatra se nepravilnom, i autori je spominju samo u tom kontekstu (Grevisse, 1973; Riegel et al. 1994)

${ }^{5}$ Ovo je naziv koji koristi jedan deo francuskih autora, a koji i mi koristimo u ovom radu zbog njegove konciznosti. Drugi naziv ovih rečenica jeste propositions conjonctives introduites par que (Wagner-Pinchon 1962; Delatour et al. 1991).

${ }^{6}$ Upravna reč može biti i imenica slične semantike.

${ }^{7}$ Prevod autora rada.
} 
1. Il craignait que les façons un peu insignifiantes, monotones, et comme définitivement fixées, (...) ne finissent par tuer en lui cet espoir romanesque. (Proust, 1954 : 256)

1a. Temeva che i modi piuttosto insignificanti, monotoni e come fissati per sempre (...) rischiassero di soffocare in lui quella romanzesca speranza. (Proust it. 2, 2010 : 43)

1b. Plašio se da pomalo beznačajni, jednolični i nekako konačno utvrđeni način njegovog ophođenja (...) ne ubije najposle u njemu onu romantičnu nadu. (Proust sr. 2004, : 42)

2. Car elle redoutait qu'on $\boldsymbol{n} \boldsymbol{e}$ fût à la questionner, à la soigner, qu'on $\boldsymbol{n} \boldsymbol{e}$ la quittât plus. (Flaubert, 1999 : 151)

2a. Temeva che le facessero domande, che volessero curarla, che non la lasciassero più in pace. (Flaubert it., $2002: 170$ )

2b. Jer se poboja da je Šarl ne počne pitati, nadgledati, da $\boldsymbol{n} \boldsymbol{e}$ ostane pored nje. (Flaubert sr., $2006: 184$ )

3. J'avais peur qu'elle s'empale sur elle-même. (Pennac, $1989: 259$ )

3a. Avevo paura che impalasse su se stessa. (Pennac it., $2014:$ 190)

3b. Plašio sam se da će (...) nabiti samu sebe na kolac. (Pennac sr., $2001: 218$ )

Primeri pokazuju da je upotreba ekspletivnog ne nakon glagola bojazni u francuskom, iako fakultatativna (primer 3 je ne sadrži), ipak rasprostranjena. Italijanske ekvivalentne strukture nikada ne sadrže ekspletivnu negaciju, niti se takva mogućnost pominje u literaturi. Sa druge strane, u srpskom je upotreba ekspletivnog ne nakon glagola bojazni obavezna : uobičajena struktura je $d a+n e+$ prezent glagola svršenog vida $(1 \mathrm{~b}, 2 \mathrm{~b})^{8}$. Moguće je postići istovetnu semantiku bez upotrebe ekspletivnog ne, ali tada više nije moguća konstrukcija sa prezentom, nego je obavezna upotreba futura (3b).

Ipak, uz upotrebu futura (u kojoj nema mogućnosti za ekspletivnu negaciju) semantika glagola plašiti se može biti i izmenjena (ili makar ublažena) ${ }^{9}$. Tako primer (3b) možemo interpretirati i kao : Činilo mi se/izgledalo mi je da će (...)

${ }^{8}$ Vrednost prezenta u ovoj konstrukciji u srpskom nije indikativna nego modalna, što korespondira sa upotrebom sibžonktiva/konjunktiva posle glagola bojazni u francuskom i italijanskom jeziku. O tome videti više u: Seder, 2011.

${ }^{9}$ Do sličnih zaključaka (ali vezanih za glagole straha i dopunu u obliku negiranog perfekta) dolazi i N. Milošević, analizirajući primere tipa Plašim se da nije položio ispit (Milošević, 1997 : 43). 
nabiti samu sebe na kolac, dok u konstrukciji $d a+n e+$ prezent glagola svršenog vida takve dvosmislenosti nema: Plašio sam se da ne nabije samu sebe na kolac.

\section{1.b. Glagoli kojima se sprečava ili negira realizacija neke radnje}

Kao što je već rečeno, reč je o glagolu empêcher (sprečiti) i glagolima srodne semantike, kao i glagolima nier (poricati) i douter (sumnjati) u odričnom ili upitnom obliku. Iako autori navode mogućnost upotrebe ekspletivnog ne nakon ovih glagola (Grevisse, 1973; Delatour - Jennepin - Léon - Dufour - Mattlé Yeganeh - Teyssier, 1994 ), u jezičkoj realizaciji to nije čest slučaj (Zonko Dilković - Ilc, 2017), što je pokazala i malobrojnost primera iz našeg kopusa:

4.En s'attachant M. Bovary par des politesses, c'était gagner sa gratitude, et empêcher qu'il ne parlât plus tard, s'il s'apercevait de quelque chose. (Flaubert : 5859)

4a. Fare delle gentilezze al signor Bovary significava assicurarsene la gratitudine e chiudergli la bocca nel caso si fosse accorto di qualcosa. (Flaubert it., 2002: 73) 4b.Pridobiti gospodina Bovarija uslužnošću, značilo je zaslužiti njegovu zahvalnost i sprečiti ga da $\boldsymbol{n} \boldsymbol{e}$ govori, ako kasnije nešto primeti. (Flaubert sr. 2006 : 80)

5. Quand sa maitresse du moment était au contraire une personne mondaine ou du moins une personne qu'une extraction trop humble ou une situation trop irrégulière n'empêchait pas qu'il fît recevoir dans le monde, ... (Proust, $1954: 231$ )

5a. Quando la sua amante del momento era, invece, una donna di mondo o almeno una personna cui una troppo umile estrazione o una situazione troppo irregolare non intralciassero una presentazione nella buona società, ... (Proust it. 2, $2010: 10$ )

5b. Kada bi mu trenutna ljubavnica bila osoba iz otmenog sveta ili bar osoba kojoj suviše skromno poreklo ili odviše nepoćudan društveni položaj ne bi branili da je on uvede u otmeni svet... (Proust sr. 2004, : 12)

Damuret i Pišon (Damourette - Pichon, 1911 : 36) daju objašnjenje za slučajeve izostavljanja ekspletivnog ne u kompletivnoj rečenici negiranog glagola empêcher. Oni naime tvrde da se ekspletivno ne javlja samo kada do sprečavanja ne dođe zbog nedovoljno jake zaprečne tendencije, a ne i onda kada do njega ne dođe zato sto zaprečna tendencija i ne postoji: Je n'empêche pas que tu le mettes (sc. ton costume neuf), aujourd'hui, mais il ne faudrait pas que ce soit tout le temps)/Ne branim ti da ga obučeš (sc. tvoj novi kostim) danas, ali ne bi trebalo da ga nosiš stalno (Damourette - Pichon, 1911-36 : 516).

Kada je reč o ekspletivnom ne nakon negiranog glagola douter, Damuret i Pišon smatraju da se njegova upotreba u ovoj situaciji može objasniti kao jedna 
vrsta psihološke pobune protiv kategoričnosti izjave: Je ne doute pas/Ne sumnjam. $\mathrm{U}$ tom smislu, primeri upotrebe bez ne javljaju se kada ovakve pobune nema:

6. Ne doutant pas que ce fût pour montrer qu'ils n'étaient pas intimidés par les titres, elle souhaitait d'imiter leur fierté. (Proust, $1954: 26$ )

6a. Non avendo il minimo dubbio che questo stesse a mostrare che loro non erano in soggezione davanti ai titoli nobiliari, lei agognava a imitare tanta fierezza. (Proust it., 2010 : 86)

6b. Ne sumnjajući da oni to čine zato da bi pokazali kako se oni ne ustručavaju s'titulama, želela je da i sama podražava njihovoj gordosti . (Proust sr. 2004 : 81)

U skladu sa navodima literature, ekpletivno ne nakon glagola empêcher, kao i glagola nier $i$ douter u dubitativnoj konstrukciji veoma je retko. U italijanskom jeziku se mogućnost njegove upotrebe nakon ovih glagola ni ne pominje. U srpskom pak, iako se ekspletivno ne posle ovih glagola ne očekuje, ono se javilo u jednom primeru (4b). Ipak, s obzirom na to da bi prirodnija bila rečenica : Pridobiti gospodina Bovarija uslužnošću, značilo je zaslužiti njegovu zahvalnost $i$ (tako) učiniti da ne govori, ako kasnije nešto primeti, ovu upotrebu ekpletivnog ne možemo smatrati osobenošću prevodivočevog stila i/ili uticajem polaznog jezika.

\subsection{Finalne rečenice}

U finalnim rečenicama ekspletivno ne javiće se samo ukoliko su uvedene vezničkim izrazima de crainte que i de peur que. Kao što se na osnovu njihovog sklopa može pretpostaviti, oni uvode rečenicu koja izražava rezultat koji se želi izbeći - le but à eviter (Točanac Milivojev, 1989 : 125).

7. Quant aux très beaux, tout le monde les regarde, mais ils n'osent regarder personne, de peur qu'on $\boldsymbol{n} \boldsymbol{e}$ leur saute dessus. (Pennac, 1989 : 176)

7a.Quanto ai molto belli, tutti li guardano, ma loro non osano guardare nessuno, per paura che gli si salti adosso. (Pennac it., 2014 : 130)

7b.A veoma lepe svi gledaju, samo oni ne gledaju nikoga, jer se plaše da će ih ovi odmah spopasti. (Penak, 2001 : 146)

/...jer se plaše da ih odmah ne spopadnu.

8. Elle se tenait immobile, de peur que la moindre émotion ne la fît vomir. (Flaubert : 239)

8a. Rimaneva immobile, temendo che la più piccola emozione la facesse vomitare. (Flaubert it. : 239) 
8b.Ležala je nepomično, bojeći se da je i najmanje uzbuđenje ne natera na povraćanje. (Flaubert sr. : 279)

Sintaksa finalnih rečenica uvedenih veznicima de peur/crainte que istovetna je kao i sintaksa kompletivnih rečenica uvedenih glagolima bojazni: u francuskom je uobičajena upotreba ekspletivnog ne, u italijanskom nije moguća, a u srpskom jeziku ona je obavezna uz perfektivni prezent (uz mogućnost njegovog izostavljanja, što iziskuje promenu glagolskog oblika).

\subsection{Temporalne rečenice}

Nada Milošević (Milošević, 1997) upotrebu ekspletivnog ne u vremenskim rečenicama proučava razmatrajući temporalne rečenice uvedene veznicima avant que, jusqu'à ce que i tant que. Ono što je zajedničko ovim rečenicama, jeste to što one ukazuju na činjenicu da je radnja glavne rečenice aktuelna do momenta realizacije radnje zavisne rečenice (Stanojčić - Popović, 1994 : 309) ${ }^{10}$.

Kada je reč o francuskom, ekspletivno ne u temporalnim rečenicama se javlja samo nakon veznika avant que, i to fakultativno. U narednim primerima razmotrićemo ekvivalentne rečenice u italijanskom i srpskom jeziku.

2.3.a. veznik avant que (ne)

9. Il se passa une bonne quinzaine de jours avant que Krämer $\boldsymbol{n}$ 'ouvrît le livre. (Pennac, $1989:$ 341)

9a. Passarono quindici giorni prima che Krämer aprisse il libro. (Pennac it., 2014 : 255)

9b. Prošle su dobre dve nedelje pre nego što je Kramer otvorio knjigu. (Pennac sr., $2001: 67)$

10. Elle cueillit précipitamment (...) un dernier chrysanthème et le lui donna avant qu'il fût reparti. (Proust, $1954: 285$ )

10a. Odette colse (...) un ultimo crisantemo, e, prima che rispartisse, glielo porse. (Proust it. 2, $2010: 37$ )

10b. On hitro uzbra (...) poslednju hrizantemu što je tu cvetala i dade mu je pre nego što su kola pošla. (Proust sr. 2004, : 42)

\footnotetext{
10 Pomenuti autori analiziraju ove rečenice kao rečenice koje označavaju posteriornost, pridajući im značenje mere vremena.
} 
11. On ne retournerait pas à Paris avant que le divisionnaire Coudrier les ait lues. (Pennac, 1989 : 341)

11a. Sarebbero tornati a Parigi soltanto dopo che Coudrier le avesse lette. (Pennac it., $2014: 270$ )

11b. Nema povratka u Pariz pre nego što ih načelnik Kudrije pročita. (Pennac sr., $2001: 307$ )

Primeri iz korpusa pokazuju, s jedne strane, da upotreba ekspletivnog ne nakon veznika avant que jeste fakultativna, i da njegovo izostavljanje ne iziskuje nikakve sintaksičke promene niti menja semantiku iskaza. Sa druge strane, primeri pokazuju da su ekvivalentne rečenice u italijanskom temporalne rečenice uvedene vetnikom prima che, a u srpskom rečenice uvedene veznikom pre nego što, u oba jezika bez mogućnosti upotrebe ekspletivnog ne.

Ipak, u primeru (11b), s obzirom na negativnu konotaciju upravne rečenice, moguć je i sledeći prevod: Nema povratka u Pariz/Neće se vratiti u Pariz (sve) dok ih načelnik Kudrije ne pročita. Naime, rečenice uvedene veznikom sve dok izražavaju situaciono-uslovnu terminativnost, koja je ,naročito izražena u rečenicama sa obe negirane nerealizovane predikacije, rečenična u futuru 1 (retko u prezentu koji upućuje na budućnost), ili kao struktura sa modalnim glagolom, a zavisna predikacija u futuru 2 ili perfektivnom prezentu ${ }^{11 ، “}$ (Antonić, 2013 : 342).

\section{3.b. veznici jusqu'à ce que $i$ tant que}

Vremenski odnos koji je u prethodnom primeru izražen veznikom avant $q u e, \mathrm{u}$ francuskom se izražava prevashodno temporalnim rečenicama uvedenim veznicima jusqu'à ce que ${ }^{12} \mathrm{i}$ tant que (uz negativnu predikaciju ${ }^{13}$ ). Reč je o rečenicama koje pokazuju do kada će trajati radnja upravne rečenice, te je njihovo obeležje terminativnost. Prema literaturi, ovaj vremenski odnos se u italijanskom jeziku izražava temporalnim rečenicama uvedenim veznicima finché, fino a che, fino a quando, fin quando, fintanto che/sino a quando „često pojačanim pleonastičkim non" (Terić, $2005: 212$ ).

\footnotetext{
${ }^{11}$ Nećeš dobiti posao (sve) (dotle) dok ne završiš školu. (Antonić, 2013 : 342).

12 Iako neki autori (Milošević, 1997 : 54) beleže primere ekspletivnog ne uz ovaj veznik, u drugim izvorima nismo zabeležili takvu napomenu niti smo zabeležili takav primer u našem korpusu.

$13 \mathrm{Uz}$ afirmativnu predikaciju ovaj veznik izražava simultanost : Vous prendrez ce médicament tant que la fièvre durera (Delatour et al., 1991 : 268).
} 
12. Il s'ajourna de semaine en semaine, jusqu'à ce qu'il reçût une seconde lettre maternelle. (Flaubert, $1999: 821$ )

12a. Rimandò la partenza di settimana in settimana, finché non ricevette una seconda lettera dalla madre. (Flaubert it., 2002 : 98)

12b. Leon stade odlagati svoj polazak od nedelje do nedelje, sve dok od matere nije dobio i drugo pismo. (Flaubert sr., 2006 : 107)

/* Leon stade odlagati svoj polazak od nedelje do nedelje, sve dok je od matere dobio i drugo pismo.

13. Je sais qu'elle ne dira rien d'autre tant qu'elle n'aura pas vu Clarence. (Pennac, $1989: 70)$

13a.So che non dirà altro fino a quando non avrà visto Clarence. (Pennac it., 2014 : 51)

13b. Ja znam da neće ništa drugo izgovoriti sve dok ne bude videla Klarensa. (Pennac sr., $2001:$ 57)

U slučaju izostavljanja ekspletivne negacije (Ja znam da neće ništa drugo izgovoriti sve dok bude videla Klarensa), implicirao bi se odnos simultanosti dve predikacije : Ja znam da neće ništa drugo izgovoriti dokle god vidi Klarensa).

Kao što primeri i pokazuju, u srpskom jeziku posle veznika sve dok (u značenju terminativnosti) upotreba ekspletivne negacija je obavezna.

Ipak, autori navode i primere u kojima je upotreba ekspletivnog ne fakultativna, tačnije u kojima ,izostavljanje elementa ne ne smeta današnjem govorniku srpskog jezika“ (Milošević, 1997 : 48): Stoj tu dok (ne) dođem (Popović, 1994 : 191-192), Ostaću ovde dok se Zoran (ne) vrati (Stanojčić - Popović, 1994 : 309). I. Antonić (Antonić, 2001 : 170-191) detaljno se bavi temom fakultativnosti/obaveznosti ekspletivne negacije u ovim konstrukcijama, te navodi kriterijume za njihovo razlikovanje. Zaključak do kojeg dolazi jeste taj da ona jeste fakultativna uz nepunktualnu perfektivnu predikaciju (realizacija predikacije zahteva izvesno vreme), kao u primeru: Ja sam mnogo tražio o njemu dok (ni)sam nešto prikupio, za razliku od punktuelne predikacije, gde je ona obavezna (A on odmicaše sve više i više dok se ne izgubi).

\subsection{Komparativne rečenice za nejednakost}

U komparativnim rečenicama za nejednakost uvedenim pomoću que u korelaciji sa adverbima koji označavaju nejednakost (autre, plus, moins, plutôt,$\ldots$ ) koristi se ekspletivno ne samo ukoliko je glavna rečenica u afirmativnom obliku. $\mathrm{U}$ 
tom slučaju, stanje stvari izraženo zavisnom rečenicom biva negirano u odnosu na istinu koja je izrečena glavnom rečenicom : Elle est plus grande que je ne le pensais. = Je ne pensais pas qu'elle fût si grande (Riegel - Pellat - Rioul, 1994 : 420).

Iako se i u literaturi vezanoj za francuski i u onoj vezanoj za italijanski ekspletivna negacija navodi kao fakultativna, ona se $\mathrm{u}$ francuskom jeziku nalazi $\mathrm{u}$ svim primerima iz našeg korpusa, a u italijanskom jeziku izostavljena je samo u jednom primeru (16a) :

14. On dort toujours plus qu'on $\boldsymbol{n} \boldsymbol{e}$ le croit, dans la vie. (Pennac, 1989: 83)

14a. Si dorme sempre più di quanto non si creda, nella vita. (Pennac it., $2014: 61$ )

14b. Čovek u životu uvek spava duže nego što mu se čini. (Pennac sr., 2001 : 67)

15. Il ne discutait pas ses idées ; il acceptait tous ses goûts ; il devenait sa maîtresse plutôt qu'elle $\boldsymbol{n}$ 'était la sienne. (Flaubert, 1999 : 206)

15a. Non discuteva le idee di Emma; accettava i suoi giudizi e, in questo amore, la parte della donna era più sua di quanto non lo fosse di lei. (Flaubert it., 2002 : 226)

15b. On se nje upuštao u ocenu njenih ideja; on je primao sve njene želje; bio je njena metresa više nego što je ona bila njegova. (Flaubert sr., $2006: 246$ )

16. Vraiment tu es bien moins intelligente que je $\boldsymbol{n} \boldsymbol{e}$ croyais! (Proust, $1954: 321$ )

16a. Sul serio, sei molto meno intelligente di quanto penssassi! (Proust it. 2, 2010 : 37)

16b. Zbilja, ti si mnogo manje inteligentna nego što sam verovao! (Proust sr. 2004, : 42)

U srpskom jeziku, naprotiv, u ovoj situaciji nije moguća upotreba ekspletivnog ne. Koriste se isključivo veznici nego, negoli, $n o^{14}$.

\subsection{Hipotetičke rečenice posle veznika à moins que}

Hipotetičke rečenice uvedene ovim veznikom izražavaju pretpostavku koja sprečava odvijanje radnje glavne rečenice (Točanac Milivojev, 1989 : 144). Dakle, radnja glavne rečenice se neće realizovati jedino u slučaju realizacije radnje zavisne

\footnotetext{
14 Ovi veznici izgubili su odrično značenje, ali im je poreklo isto kao i poreklo jednočlane negacije (od praindoevropskog ne). Više o ovome videti u: Milošević, 1997 : 57.
} 
rečenice (koja je postavljena kao pretpostavka). Veznik a meno che se u italijanistici svrstava u veznike koji uvode isključne rečenice - it. proposizioni eccettuative, koje ograničavaju sadržaj upravne rečenice, ukazujući na moguć izuzetak od onoga što je njome rečeno (Terić, 2005 : 238). S obzirom na opisanu semantiku ovog veznika, a uzevši u obzir njegovu klasifikaciju u italijanistici, smatramo da bi adekvatan naziv za ove rečenice bio i isključno-hipotetičke (ili isključno-uslovne) rečenice.

Prema literaturi, i u francuskom i u italijanskom jeziku može se javiti ekspletivno ne:

17. Mais Swann et la princesse avaient une même manière de juger les petites choses qui avait pour effet - à moins que ce ne fût pour cause - une grande analogie dans la façon de s'exprimer et jusque dans la prononciation. (Proust, 1954 : 397) 17a. Ma Swann e la principessa avevano una stessa maniera di gudicare le piccole cose che aveva come conseguenza - a meno che non l'avesse come causa - una grande analogia nel modo di esprimersi, che arrivava ad affermarsi persino nella pronuncia delle parole. (Proust it. 2, $2010: 169$ )

17b. Ali Svan i princeza na isti su način sudili o sitnim stvarima, čija je posledica bilo to da su imali mnogo sličnosti u načinu izražavanja, čak i u izgovoru, sem ako ovo nije bilo uzrok onome. (Proust sr. 2004, : 156)

U sledećim primerima zavisna rečenica je parcelizovana :

18.- Avez-vous la moindre idée des raisons pour lesquelles on a tiré sur Malaussène?

- Pas la moindre, non. (...) A moins qu'on $n$ 'ait voulu abattre une image. (Pennac, 1989 : 191)

18a.-Ha qualche idea sulle ragioni per cui qualcuno ha sparato a Malaussène?

-No, nessuna. (...) A meno che non si sia voluto distruggere un'immagine. (Pennac it., 2014 : 139-140)

18b. „Imate li bilo kakvu predstavu o tome zašto bi neko pucao na Malosena?“ „Nikakvu“ (...),Osim ako neko nije hteo da sruši sliku“. (Pennac sr., 2001 : 157-158)

19. Il n'y a qu'une explication possible, Thian. (...) Elle couvre quelqu'un. (...) À moins qu'ils $\boldsymbol{n}$ 'aient cherché à nous balader. (Pennac, 1989: 293 )

19a. C'è una sola spigazione possibile, Thian. (...) La Corrençon copre qualcuno. (...) A meno che non abbiano cercato di sviarci. (Pennac it., 2014 : 217-218)

19b. Postoji samo jedno objašnjenje.(...) Ona štiti nekoga. (...) Osim ako nas ne vozaju. (Pennac sr., $2001: 248$ ) 
20. Seulement, je pensais qu'elle en dédierait l'exemplaire original à un boutonneux imprécis - baskets et walkman - qui tomberait sous autorité du frère en succombant au charme de la sœur. À moins que Clara (...) ne nous ramenât un fort en thème un peu guindé. (Pennac, 1989: 41)

20a. Pensavo però che ne avrebbe dedicato l'originale a un qualche non ben definito brufuloso - scarpe da ginnastica e walkman - che sarebbe finito sotto l'autorità del fratello mentre soccombeva al fascino della sorella. A meno che Clara (...), non ci portasse in casa un secchione un po sostenuto. (Pennac it., $2014: 29-30$ ) 20b. Samo, mislio sam da će njegov prvi primerak pokloniti nekom bubuljičavku - $\mathrm{s}$ patikama i vokmenom - koji će podleći autoritetu brata zajedno sa čarima sestre. Osim ako nam Klara (...) ne bi dovela kakvog pomalo uštogljenog odlikaša.

Za razliku od prethodnih vrsta zavisnih rečenica, kod (isključno-) hipotetičkih rečenica uvedenih veznikom à moins que i ekvivalentnih struktura $\mathrm{u}$ italijanskom i srpskom jeziku ekpletivno ne se po pravilu javlja, tako da možemo zaključiti i da je ono, ako ne obavezno, svakako blisko jezičkom osećaju govornika sva tri posmatrana jezika.

\section{ZAKLJUČNA RAZMATRANJA}

Pojava ekspletivne negacije karakteristika je sva tri posmatrana jezika. Kada je reč o njenoj pojavi u ekvivalentnim strukturama, analiza korpusa pokazala je sledeće :

a. postoje sintaksička okruženja u kojima se ekspletivna negacija javlja samo $\mathrm{u}$ francuskom jeziku: ovo se dešava u kompletivnim rečenicama nakon glagola empêcher, douter i nier, s tim što je korpus potkrepio navode literature da je sa ovim glagolima ekspletivna negacija veoma retka;

b. postoje sintaksička okruženja u kojima se ekspletivna negacija javlja u francuskom i italijanskom jeziku : reč je o komparativnim rečenicama za nejednakost. Njihovo stvarno značenje jeste to da predikacija zavisne rečenice biva negirana tvrdnjom koju iznosi glavna rečenica. U srpskom jeziku formalno nema ekspletivne negacije, ali je ona sadržana u veznicima koji uvode komparativnu rečenicu: nego, negoli, no.

c. postoje sintaksička okruženja u kojima se ekspletivna negacija javlja u francuskom i srpskom jeziku: reč je o kompletivnim rečenicama nakon glagola bojazni kao i o finalnim rečenicama uvedenim vezničkim 
sklopovima čiji je konstituent imenica sa značenjem bojazni (de peur que, de crainte que);

d. postoje sintaksička okruženja u kojima se ekspletivna negacija javlja u italijanskom i srpskom jeziku: reč je o temporalnim rečenicama sa značenjem terminativnosti. Iako se ovo značenje $u$ francuskom izražava veznicima jusqu'à ce que, tant que (uz negativnu predikaciju), i (u nekim kontekstima) veznikom avant que, samo uz veznik avant que može se javiti ekspletivna negacija. U italijanskom jeziku su rečenice sa ovim obeležjem uvedene veznicima finché (fino a che), fino a quando (finquando), koji su po pravilu praćeni pleonastičkim non. U srpskom jeziku ekvivalentni veznik sve dok obavezno je praćen ekspletivnim ne;

e. postoje sintaksička okruženja u kojima se ekspletivna negacija javlja u sva tri posmatrana jezika: ovo se dešava u isključno-hipotetičkim rečenicama, koje navode onu okolnost (uslov) koja bi mogla da isključi realizaciju radnje glavne rečenice.

Kada je reč o (ne)obaveznosti ekspletivne negacije, iako je ona u oba romanska jezika uvek fakultativna, u gorenavedenim situacijama veoma je frekventna, a postoje konstrukcije (isključno-hipotetičke rečenice) u kojima nismo pronašli nijedan primer njenog ispuštanja.

U srpskom jeziku ona je obavezna posle glagola bojazni (kao i nakon veznika čiji je kostituent imenica strah). Izostavljanje ekpletivne negacije u ovoj situaciji jeste moguće, ali uz promenu načinsko-temporalne orijentacije predikata, ali i moguću dvostruku interpretaciju celog iskaza. U temporalnim rečenicama koje označavaju terminativnost nakon veznika sve dok upotreba ekspletivne negacije je obavezna.

Najzad, s obzirom na to da postoji veliki procenat poklapanja u pojavi ekspletivne negacije u francuskom i italijanskom jeziku (što znači da je javlja u istovetnim sintaksičko-semantičkim uslovima), kao i to da ona, kada se javi, uvek sa sobom nosi implicitnu negaciju, iako jeste fakultativna, ne može se govoriti o njenoj suvišnosti ili semantičkoj ispraznosti, nego jedino o redundantnosti iskaza koji je sadrže. 
Ružica Seder

SUR LA NÉGATION EXPLÉTIVE EN FRANÇAIS, ITALIEN ET EN SERBE

\section{Résumé}

Cet article porte sur le phénomène de négation dite « explétive », formalisée dans la langue par l'emploi de l'adverbe ne (discordantiel) et omission du forclusif. Vu qu'il ne s'agit pas de la vraie négation, l'emploi de l'élément ne est facultatif, et souvent considéré comme « pléonastique, redondant » ou même « abusif ». Pourtant, l'analyse du corpus montre que la négation explétive est largement utilisée dans les trois langues considérées, et souvent dans les contextes identiques, ce qui prouve que son emploi peut être justifié par des données psychologiques, ce qui dépasse une contrainte formelle ou un effet de style.

Mots-clés: négation explétive, négation pléonastique, négation phraséologique, français, italien, serbe 


\section{LITERATURA}

Antonić, I. (2001). Vremenska rečenica, Novi Sad/Sremski Karlovci: Izdavačka knjižarnica Zorana Stojanovića.

Antonić, I. (2013). Neke modifikacije vremenskog odnosa u rečenici s temporalnom klauzom, U: Južnoslovenski filolog, LXIX, 335-345.

Damourette, J., Pichon, E. (1911-1936). Des mots à la pensée, Essai de Grammaire de la Langue Française, Tome cinquième, VERBE (fin), Paris: Bibliothèque du français moderne, Collection des linguistes contemporains.

Delatour, Y., Jennepin D., Léon-Dufour M., Mattlé-Yeganeh, A. \& Teyssier, B. (1991). Grammaire du Français (Cours de civilisation française de la Sorbonne), Paris: Hachette.

Dubois, J., Lagane, R. (1993). La nouvelle grammaire du français. Paris : Larousse. Grevisse, M. (2073). Le français correct, Bruxelles: Editions J. Duculot.

Mauger, G. (1968). Grammaire pratique du français d'aujourd'hui, 4e édition, Paris: Hachette.

Milošević, N. (1997) Negacija predikata u francuskom $i$ srpskom jeziku, Magistarski rad odbranjen na Filološkom fakultetu u Beogradu (rukopis) .

Musić, A. (1933) Rečenice bojazni u grčkom, latinskom i srpskohrvatskom jeziku, Zagreb: Tisak nadbiskupske tiskare.

Papić, M. (1992). Gramatika francuskog jezika. Strukturalna morfosintaksa. Beograd: Zavod za udžbenike i nastaavna sredstva, Novi Sad: Zavod za izdavanje udžbenika.

Poisson-Quinton S., Mimran, R. \& Mahéo-Le Coadic, M. (2004). Grammaire expliquée du français. Paris : SEJER.

Popović, M. (1994). Kriteriji zasnovanosti ekspletivne („suvišne“) negacije. U: Južnoslovenski filolog, L, 189-198.

Riegel, M., Pellat, J.C. \& Rioul, R. (1994). Grammaire méthodique du français, $3^{\mathrm{e}}$ édition Paris : P.U.F.

Rigotti E., Schenone, P. (1988). Grammatica italiana [Grammaire italienne], Torino : SEI.

Seder, R. (2008). Francuski sibžonktiv i italijanski konjunktiv - poređenje upotrebe na korpusu jednog romana, U: Primenjena lingvistika, 9. 162-171.

Seder, R. (2011). Francuske kompletivne rečenice uvedene glagolima osećanja i njihovi korelati u srpskom jeziku. U: Primenjena lingvistika, 12, 126-137.

Seder, R. (2011a). Izbor glagolskog načina u francuskim kompletivnim rečenicama uvedenim glagolima govorenja, mišljenja i percepcije, i njihovi korelati u 
srpskom jeziku. U: Nasleđe, Časopis za književnost, jezik, umetnost i kulturu, 20, 303-316.

Serianni, L. (2005). (con la collaborazione di Alberto Castelvecchi): Grammatica Italiana (italiano commune e lingua letteraria). Torino : Utet.

Terić, G. (2005). Sintaksa italijanskog jezika. [Syntaxe de la langue italienne], Beograd, Filološki fakultet : Beograd.

Stanojčić, Ž., Popović, Lj. (1994). Gramatika srpskoga jezika, Treće, prerađeno izdanje, Beograd:Zavod za udžbenike i nastavne sredstva.

Točanac Milivojev, D. (1989). Propositions, phrase et texte, Syntaxe de Phrase Française, Novi Sad: ISJK.

Zovko Dinković I., Ilc G. (2017). Pleonastic negation from a cross-linguistic perspective, Jezikoslovlje, 18.1., 159-180.

Wagner, R.-L. \& Pinchon, J. (1962). Grammaire du français classique et moderne, Paris: Hachette.

Wilmet, M. (2003). Grammaire critique du français, $3^{\mathrm{e}}$ édition, Bruxelles: Duculot.

\section{IZVORI}

Flaubert : Flaubert, G. (1972). Mme Bovary, Paris : Librairie Générale française.

Flaubert it.: Flaubert, G. (2018). Mme Bovary, prevod Oddera, Bruno [5. Elektronsko izdanje,: 5 april 2018]. pristupljeno: 15. 02. 2021. http://www.liberliber.it

Flaubert sr.: Flober, G. (2006) Gospođa Bovari, preveo: Dušan L. Đokić, Beograd: Izdavačka kuća Draganić.

Pennac: Pennac, D. (1989). La petite marchande de prose, Paris: Gallimard.

Pennac it.: Pennac, D. (2014). La prosivendola, traduzione di Yasmina Malaouah, Milano: Fertinelli.

Pennac sr. Penak, D. (1999). Vilinski karabin, Prevod sa francuskog: Olivera Milićević, Beograd: Nolit.

Proust: Proust, M. (1954). À la Recherche du Temps Perdu, Tome I: Du Côté de chez Swann. Deuxième partie: Un Amour de Swann. Paris : Gallimard.

Proust it. : Proust, M. (2010). Un amore di Swann, traduzione di Oreste del Buono, Milano: Garzanti. 